\title{
RESUMO
}

SSN Digital: 2316-3828

ISSN Impresso: 2316-333X

DOI: 10.17564/2316-3828.2020v8n3p366-377

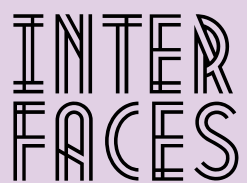

CIENTIFICAS

\section{CONTRIBUIÇ̃̃ES DA MONITORIA ACADÊMICA NA FORMAÇ̃̃O DOCENTE DE LICENCIANDOS EM CIÊNCIAS BIOLÓGICAS}

\section{CONTRIBUTIONS OF ACADEMIC MONTORING IN THE TEACHER TRANING OF A BIOLOGICAL SCIENCE COURSE}

\section{CONTRBBUCIONES DE MONTORÍA ACADÉMICA EN LA FORMACIÓN DOCENTE DE LOS ESTUDIANTES DE LICENCIATURA DE UN CURSO DE CIENCIAS BIOLÓGICAS}

Jones Baroni Ferreira de Menezes ${ }^{1}$ Francisca Daniela Lira Mota ${ }^{2}$
A participação em programas de monitoria acadêmica contribui para a formação docente, além de possibilitar a realização de atividades de ensino, pesquisa e extensão, complementando o papel do docente e criando uma relação bilateral de aprendizagem. Assim, o presente trabalho objetivou analisar as contribuições do programa de monitoria acadêmica na formação docente para os discentes monitores de um curso de Ciências Biológicas. Para isso, aplicou-se um questionário aos 10 estudantes que realizaram o exercício da monitoria em disciplinas no curso em questão, durante o ano de 2016. Os monitores alegaram optar pela monitoria devido às horas complementares, afinidade com a disciplina (9 alunos) e oportunidade de aperfeiçoar a formação docente ( 6 alunos) além de, em unanimidade, corroborarem como importante contribuinte da formação para o fazer docente, propiciando a compreensão da diversificação metodológica e dinamização das aulas das disciplinas contempladas com monitoria. Dessa forma, os resultados apontam para uma positiva contribuição da monitoria acadêmica na formação docente dos futuros professores.

\section{PALAVRAS-CHAVE}

Biologia. Docência. Formação. 


\section{ABSTRACT}

Participation in contribution programs for teacher education, such as the academic monitoring project, helps students to develop their own didactics and to promote their training, performing teaching and extension research activities, complementing the role of the teacher and creating a bilateral relationship of learning. Thus the present work aimed to analyze the contributions of the academic monitoring program in the teacher training for the student monitors of a Biological Sciences course. To that end, a questionnaire was applied to the 10 students who carried out the monitoring exercise in subjects in the course in question during the year 2016. The monitors claimed to opt for monitoring due to the complementary hours, affinity with the subject ( 9 students) and opportunity to improve teacher education (6 students) and, in a unanimous agreement, to corroborate as an important contributor to the training to make the teacher, providing an understanding of the methodological diversification and dynamization of the classes of the disciplines contemplated with monitoring. Thus, the results point to a positive contribution of academic monitoring in the teacher training of future teachers.

\section{KEYWORDS}

Biology. Teaching. Formation.

\section{RESUMEN}

La participación en programas de contribución a la formación docente, como el proyecto de monitoreo académico contribuye al discente a desarrollar su propia didáctica y favorecer su formación, realizando actividades de investigación enseñanza y extensión, complementando el papel del docente y creando una relación bilateral de aprendizaje. Así, el presente trabajo objetivó analizar las contribuciones del programa de monitoreo académico en la formación docente para los discentes monitores de un curso de Ciencias Biológicas. Para ello se aplicó un cuestionario a los 10 estudiantes que realizaron el ejercicio de la monitoría en disciplinas en el curso en cuestión durante el año 2016. Los monitores alegaron optar por la monitoría debido a las horas complementarias, afinidad con la disciplina (9 alumnos) y oportunidad de perfeccionar la formación docente (6 alumnos) además de, en unanimidad, corroborar como importante contribuyente de la formación para el hacer docente, propiciando la comprensión de la diversificación metodológica y dinamización de las clases de las disciplinas contempladas con monitoría. De esta forma, los resultados apuntan hacia una positiva contribución del monitoreo académico en la formación docente de los futuros profesores. 


\section{PALABRAS-CLAVES}

Biología. Docencia. Formación

\section{INTRODUCÇÃO}

As universidades encaram o importante papel de preparar docentes qualificados para as mais diferentes realidades metodológicas. Nessa constante, busca por uma formação docente eficiente e intrínseca com as relações educacionais, inseparáveis do magistério.

Dessa forma é que as instituições de ensino superior promovem diversos projetos e programas que almejam este propósito, entre esses, destacam-se os projetos de iniciação à docência, para que o discente tenha real percepção da sua escolha, desenvolva o gosto pelo exercício da docência e habilidades para contornar os desafios ao longo da sua carreira profissional (NUNES, 2007).

O Programa de Monitoria Acadêmica (PROMAC) apresenta-se como significativo exemplo de projeto de iniciação à docência nos cursos de licenciatura, conferindo alicerce teórico e prático para diversas atividades indispensáveis ao desenvolvimento docente, na medida que aprimora as técnicas pedagógicas que futuramente serão utilizadas pelo licenciando na sala de aula (NASCIMENTO; BARLETTA, 2011).

As experiências vivenciadas durante a monitoria despertam no aluno uma posição crítica reflexiva. 0 docente em formação norteia-se a partir do seu professor supervisor para construir e aprimorar sua própria didática, sendo capaz de adequar-se a diferentes realidades acadêmicas (VENTURA; SILVA; GALVÃO, 2015).

Para Pimenta e Lima (2006), a atuação prática é quem melhor forma o professor, é nesse momento que ele irá construir o conhecimento nos alunos a partir do seu conhecimento, para isso deverá usar técnicas didáticas adquiridas durante sua formação, que facilitem essa troca de saberes.

É sobre essa conjuntura que a monitoria acadêmica se apresenta como programa que influencia diretamente na formação docente. Ademais, segundo Frison (2016), a monitoria oferece um aparato pedagógico, construído durante as ações realizadas, que aprimora a relação ensino aprendizagem de ambos os envolvidos e se apresenta como instrumento de formação profissional.

Durante a vivência na monitoria, o aluno também aprende a utilizar novas metodologias e a associar teoria e prática, contribuindo para que ele já possua fundamentos didáticos e dinâmicos para suas atividades profissionais. Além disso, ressalta-se a formação do professor pesquisador, estando de acordo com a base para a formação acadêmica pautada na tríade ensino, pesquisa e extensão (LIRA et al., 2015).

Partidos dos pressupostos apresentados, questionou-se se a participação da monitoria teria contribuído na formação acadêmica enquanto futuro professor da educação básica. Com isso, o presente artigo objetiva-se analisar as contribuições do programa de monitoria acadêmica no processo de formação docente de monitores de um curso de licenciatura em Ciências Biológicas, pontuando os fatores que levaram a ser monitor, descrevendo as atividades desenvolvidas durante o período da monitoria e averiguar as contribuições e influência do programa de monitoria acadêmica no processo de formação docente enquanto monitor. 


\section{PERCURSO METODOLÓGICO}

A pesquisa é do tipo exploratória, que segundo Silveira e Córdova (2009, p. 35), proporcionam “[...] maior familiaridade com o problema, com vistas a torná-lo mais explícito ou a construir hipóteses [...]", descritiva e de abordagem qualitativa.

Os partícipes da investigação foram 10 alunos-monitores do curso de licenciatura em Ciências Biológicas de uma instituição pública do Ceará, que realizaram o exercício da monitoria durante o ano de 2016 em disciplinas específicas da grade curricular do curso em questão.

Os monitores participantes da inquirição possuem idades variadas entre 19 e 40 anos, de ambos os sexos, sendo 3 do sexo masculino e 7 do sexo feminino. Eles realizaram atividade de monitoria nas disciplinas: Biologia Celular, Fisiologia Vegetal, Biofísica, duas de Etnobiologia - sendo uma remunerada e uma voluntária, Ecologia Regional, Morfologia de Espermatófitos, Microbiologia, Flora da Caatinga e Biologia Molecular, estando distribuídos entre o terceiro e nono semestre do curso. Os quais serão posteriormente citados alfanumericamente de M1, M2, M3... M10.

Para a realização da pesquisa aplicou-se um questionário, na qual os entrevistados tinham a opção de responder mais de uma resposta para cada questionamento, a pesquisa continha com o termo de consentimento livre e esclarecido, seguindo as normas éticas da resolução 510/2016.

\section{RESULTADOSE DISCUSSÃO}

Inicialmente, inquirimos sobre a escolha do curso de licenciatura em Ciências Biológicas para situar o contexto acadêmico dos entrevistados, tendo sido relatado que a opção deu-se por diferentes motivos, tais como: disponibilidade do curso na cidade na qual reside ( 4 alunos), afinidade com a disciplina (9 alunos), influência do professor da disciplina no ensino médio ( 3 alunos), influência familiar (2 alunos), entre outros fatores como está descrito nos relatos abaixo:

Por me identificar com as áreas de estudo e por incentivo de familiares. (M2)

Por ter interesse científico, e por ser um tema bastante universal. (M3)

Das opções que eu tinha foi a mais propícia. (M4)

Porque era uma disciplina que eu gostava do Ensino Médio. Além do mais, o curso de Ciências Biológicas é perto da minha casa. Este foi outro fator determinante na minha escolha. (M7)

Vasconcelos e Lima (2010, p. 338) descrevem algumas respostas de licenciandos entrevistados sobre a escolha de cursar licenciatura e analisa que:

[...] a maioria dos sujeitos afirma ter escolhido licenciatura por vocação [...]. Os licenciando, de modo geral, estão satisfeitos com o curso e acreditam que a formação recebida na universidade contribuirá significativamente para sua empregabilidade. 
Assim, percebe-se que diante de um quadro de crise nacional do magistério, a maioria dos licenciandos afirma estar satisfeita com o curso de licenciatura e manter boas perspectivas sobre a profissão escolhida, destacando também ter optado pela licenciatura muitas vezes pela disponibilidade no local onde reside, não completamente por preferência e constrói ao longo dos estudos e prática uma relação satisfatória com a docência (LOPES; ZANCUL; BIZERRIL, 2013).

No questionamento seguinte os monitores foram inquiridos sobre o tipo de bolsa voluntária ou remunerada, constatou-se haver apenas uma monitora voluntária sendo os outros nove, portanto, monitores com remuneração. Esse fator também contribui para a escolha na participação do programa de monitoria, o qual contribui para a dedicação do aluno aos processos e atividades estudantis (NASCIMENTO; BARLETTA, 2011). Como percebe-se no relato a seguir de um dos monitores: "Afeição pela disciplina, a remuneração também influenciou na minha decisão" (M7).

Oliveira, Rocha e Pereira (2014), corroborando com a afirmativa do monitor M7, descrevem em seus estudos os principais motivos que levam os discentes a optarem participar do programa de monitoria, retratando interesse por experiências docentes, horas complementares, participação em eventos de cunho científico, aprofundamento nas disciplinas de maior interesse, como também interesse na remuneração da bolsa, para fins pessoais e acadêmicos, alegando que trabalhar para manter-se poderia atrapalhar na dedicação aos estudos.

A remuneração de bolsas estudantis possibilita ao discente manter-se na faculdade, muitos fatores socioeconômicos interferem no desenvolvimento e dedicação dos alunos o que pode ser solucionado a partir da participação em programas acadêmicos com remuneração como cita o monitor M7, demonstrando ser mais um dos benefícios do programa de monitoria acadêmica.

Outro fator importante para o desenvolvimento acadêmico dos discentes é a participação em diferentes bolsas pelos alunos monitores no qual quatro monitores afirmam ter participado de demais programas de bolsas estudantis como Programa Institucional de Bolsa de Iniciação à Docência (PIBID) e Programa de Bolsas de Estudo e Permanência Universitária (PBEPU), o que permite ao discente mais preparo para atuar como profissional docente, vivências diferentes e uma visão mais ampliada das possibilidades acadêmicas e profissionais.

A inserção do licenciando em bolsas estudantis gera contrastes quanto as atividades negativas e as favoráveis:

Trata-se, sobretudo, de apresentar de modo heurístico alguns traços dominantes que percorrem as narrativas dos jovens universitários, favorecendo a ampliação do horizonte das investigações e buscando superar dicotomias e polarizações que atravessam muitos dos discursos contemporâneos recobrindo pares como: egoísmo e altruísmo, engajamento e desengajamento, ativismo e passividade, entre outros. Por outro lado, as noções de participação, engajamento e desengajamento demandam contínua revisão. (SPOSITO; TARÁBOLA, 2016, p. 1023).

Quanto à opinião dos monitores em relação ao motivo que os levou a ser monitor foi pautado, além do atrativo financeiro, citado anteriormente, principalmente, nas contribuições para a formação docente como profissional e como acadêmico o qual se manifesta nas respostas do 
quarto questionamento que discorre sobre por que o discente escolheu participar do programa de monitoria, sendo apresentados abaixo:

Porque oferece ao aluno a oportunidade de saber como é ensinar, e o aluno ver na prática como é ser um docente (M1).

Com a monitoria acadêmica tenho oportunidade de desenvolver e me parecer como um profissional na área da docência ou em outras áreas das ciências biológica[...] (M6).

Porque é um dos passos iniciais para vivenciar à docência (M9).

Nas respostas acima é nítido que o programa de monitoria acadêmica funciona como uma atividade de iniciação à docência ao passo que o monitor desenvolve as atividades de monitoria e apreende para si novas metodologias e maneiras de desenvolver-se na profissão, essa constatação corrobora com os achados de Cunha-Junior (2017), ao trazer que a prática de monitoria é comum no ensino universitário e vem sendo aprimorada para atender ao objetivo de melhor preparar acadêmicos para a docência.

Ao longo dos relatos expostos, foram evidenciadas as contribuições que a participação na monitoria agrega aos alunos monitores, por meio de novas vivências, práticas metodológicas e inserção no ambiente de ensino, atuando também como oportunidade de certificar-se ou não da profissão a seguir. Ela desperta o discente para o magistério, cumprindo assim o principal objetivo do programa nos cursos de licenciatura das universidades (PEREIRA, 2009).

As narrativas abaixo reafirmam as discussões do questionamento anterior. Ao serem questionados sobre a importância da monitoria na sua formação docente as respostas foram todas de cunho afirmativo, como observa-se nas narrativas exemplificadas abaixo:

Tem sido muito útil, pois na prática é visto como se dá aula, usando aulas prática e várias metodologias diferentes, além de despertar no bolsista o gosto por dá aula. (M1)

Ao participar de maneira ativa no planejamento e na pesquisa de atividades práticas percebo que adquiro saberes pedagógicos que serão fundamentais para minha futura prática docente. (M2)

A monitoria está me ajudando na prática da docência, uma vez que, estou exercitando a transmissão de conhecimentos. A monitoria também permite uma relação mais próxima aluno-monitor com outros estudantes, o que já simula a relação do professor com os seus alunos. (M7) Tem me mostrado o que um docente vive, os aspectos positivos e obstáculos, bem como a importância diversificação metodológica para a construção do conhecimento. (M8)

Desenvolve vínculo com o meio docente colaborando para amadurecimento profissional. (M10)

Dentro das respostas citadas é relevante a importância da construção dos saberes pedagógicos dentro das atividades de monitoria como ressaltado na resposta do monitor denominado $\mathrm{M} 2 \mathrm{e}$ a interação com o meio docente citado pelo monitor M10 ao salientar a oportunidade de amadurecimento profissional durante a formação inicial proporcionada pelas atividades de monitoria.

Os relatos de M1, M2, M7, M8 e M10 acima, confirmam com os resultado que Bolzan, Isaia e Maciel (2013), apresentam em sua pesquisa quando evidenciam que os processos formativos, desenca- 
deiam momentos de reflexão comparti-lhada, considerando-se os múltiplos contextos socioculturais que moldam a construção do saber docente para que seja aplicável na prática escolar.

É pertinente apontar, também, a atuação da diversificação metodológica nessa constante construção da didática docente, conforme salientado nos relatos dos monitores denominados M1 e M8. Ratificando com as respostas dos referidos monitores, Vaz et al( 2012) destacam que durante os ofícios da graduação o estudante se familiariza com novas estratégias metodológicas e aprende a utilizar-se disso para moldar sua prática docente. 0 que pode ser posto em prática nas atividades de monitoria e evidenciado se há eficácia.

Constata-se similarmente aos relatos anteriores, sobre a diversificação metodológica na formação docente do aluno monitor no questionamento seguinte, acerca de quais atividades foram realizadas durante a vigência da bolsa de monitoria. Os monitores citaram as seguintes atividades: elaboração de aulas práticas, construção de material didático como cartilhas e manuais sobre os conteúdos das disciplinas, atividades complementares como estudos dirigidos, grupos de estudo e pesquisas de campo para serem trabalhadas diretamente com os alunos e o auxílio do professor supervisor da monitoria.

Foram feitas aulas práticas, pesquisas bibliográficas e de campo, produção de resumo e artigo, e produção de materiais didáticos. (M1)

Pesquisa e produção de material didático. (M2)

Realização de manuais com aulas práticas, estudos de artigos relacionados com o conteúdo da disciplina, preparo de aulas práticas. (M4)

Estudos sobre conteúdo da disciplina. Confecção de estudos dirigidos. Pesquisa acadêmica na área da educação e consequentemente produção de trabalhos científicos. Apresentação desses trabalhos em eventos científicos. Grupo de estudos com alunos da disciplina. Realização de aula teórico-prática. (M7)

Em seguida questionou-se se as monitorias contribuíram para a dinamização das aulas das disciplinas monitoradas, pedindo para os monitores apresentar o motivo quando relatarem respostas de cunho afirmativo. Como ocorreu na maioria das respostas, exemplificando os diversos fatores que beneficiaram as aulas e o entendimento dos alunos como observa-se nas descrições abaixo:

Sim, as aulas se tornam mais participavas e é como se os alunos se sentissem mais à vontade. (M1)

Sim. Pois com o acompanhamento de um monitor o professor orientador tem mais autonomia de pesquisa e elaboração de atividades diferenciadas. (M2)

Sim, existe relação de teoria e prática. (M3)

As aulas práticas mostram um lado da disciplina mais na ação saindo da mesmice dos slides, fazendo o aluno ficar curioso e a curiosidade gera investigação e investigação gera conhecimento. (M6)

Sim, porque somos estimulados a produziram aulas mais dinâmicas e atrativas. (M7)

Sim, foi possível dinamizar as aulas levando novos métodos de ensino unindo a teoria à prática. (M8) 
Sim, principalmente nas aulas prática. A presença de outro aluno tendo como função auxiliar o professor deixa os alunos mais à vontade e participativos. (M9)

Sim, pois os alunos interagem mais e conseguem aprender o conteúdo com facilidade. (M10)

Como foi citado pelos monitores entrevistados, a monitoria contempla os fatores já citados de maneira a aperfeiçoar o ensino e a formação do aluno monitor, corroborando com Souza e Nery (2016, p. 90), ao descrever que:

Os programas de monitoria têm em seus objetivos o potencial de contribuir significativamente na formação inicial de professores para o magistério de nível superior. Partindo disso, a monitoria estabelece uma relação intrínseca à formação docente e qualidade de ensino, haja vista as habilidades, competências e experiências com a prática docente que incentivam condições de um monitor pensar e refletir as práticas necessárias a ação docente.

Nesse contexto, é essencial valorizar a monitoria como espaço contemplador da formação inicial docente, de modo a garantir-lhe o reconhecimento necessário para sua melhoria e sequência do desenvolvimento efetivo de suas atividades para monitores em exercício, com o fito de acrescentar novos saberes tais como as tecnologias dentro da formação de professores.

Por meio das respostas sobre a relação da monitoria com a dinamização das aulas é possível inferir que a monitoria contribui substancialmente para a formação integrada dos monitores e dos alunos, no tocante de novas possibilidades, auxílio e interação. Tal propósito revela na monitoria uma experiência singular e decisiva para o progresso do monitor durante e após a ocorrência do programa e para seu estímulo pessoal em desenvolver-se na carreira docente (FRISON; MORAES, 2011).

Dentro das falas dos discentes M3 e M8, é destacada a importância das aulas práticas de biologia, considerando que os conteúdos biológicos constantemente tornam-se abstratos, dificultando a compreensão dos alunos, no qual se encontram nessa modalidade de aula uma alternativa para aproximar e demonstrar a teoria estudada para a turma, como maneira de comprovar os conceitos e aplicá-los na realidade de cada aluno, contextualizando o ensino. Essa prerrogativa corrobora com as pesquisas de Hermel et al (2016, p. 181) quando salienta que "a experimentação é essencial para o ensino de ciências/biologia".

Para os monitores, ampliou-se a participação deles nas aulas experimentais, a partir da participação no programa de monitoria acadêmica, tendo melhor acesso ao laboratório de biologia e a práticas da disciplina e do professor. Essas ações fornecem embasamento para que o discente saiba como manejar os componentes laboratoriais essenciais de uma prática biológica, podendo aplicar esses conhecimentos futuramente em sua metodologia docente.

A realização de aulas práticas ultrapassa a simples ilustração do que a teoria pressupõe: a observação, vivências e constatações práticas acarretam conhecimentos próprios que devem ser devidamente planejados para um propósito delimitado e conciso na aprendizagem dos alunos, estimulando o potencial pesquisador e investigativo (PAGEL; CAMPOS; BATITUCCI, 2015). 
Ademais, os relatórios gerados a partir dessas atividades também favorecem uma escrita cientifica crítica e reflexiva, de modo a despertar a curiosidade no desenvolvimento de atividades científicas e de produção acadêmica, construindo ações educativas.

Assim, atualmente, até mesmo no ensino superior, a educação apresenta diversas características de ensino tradicional. Devido a isso, com o passar do tempo os alunos tendem a perder o interesse pelas aulas, pois além de seus conhecimentos não serem valorizados e sua participação não ser instigada, não são utilizados diferentes recursos e metodologias para a incrementação das aulas (PINTO; SILVA, 2016).

0 auxílio do monitor é fundamental para que o docente tenha mais tempo e assistência na elaboração das atividades, além de ter na figura do monitor um intermédio facilitador principalmente para os alunos da disciplina.

No decorrer das diversas mudanças ocorridas nos processos de formação docente na história do Brasil, percebe-se que sempre houve e há a necessidade de adequar-se ao modelo social vigente e às exigências que surgem no ambiente educacional, na tentativa de minimizar problemáticas como a qualidade da formação inicial, os recursos e projetos disponíveis para aperfeiçoar a formação do licenciando e as ferramentas que serão discutidas a seguir.

\section{CONSIDERAÇ̃̃ES FINAIS}

É precípuo destacar que os monitores pesquisados corroboram com a premissa da importância de participar do PROMAC como complementação da formação inicial docente, de modo a aprofundarem seus conhecimentos acerca do trabalho docente, perpassando pelos planejamentos de ensino, execução e avaliação do processo de ensino e aprendizagem.

Do mesmo modo, há um impacto formativo positivo para os alunos monitorados e o professor orientador, tornando a monitoria um processo participativo e colaborativo.

Ademais, eles relatam que a monitoria traz inúmeras contribuições, agregando novas metodologias de ensino, recursos, habilidades e meios de orientar e apreender saberes, facilitando seu processo de fazer docente e preparo didático por meio de um programa acadêmico com caráter de iniciação docente que aperfeiçoa o desenvolvimento estudantil e profissional.

Nesse sentido, foi exposto que as principais atividades realizadas durante o exercício da monitoria e analisadas no processo de ensino destacam-se: as aulas práticas, a construção de material didático, participação em atividades de extensão e em eventos acadêmicos, o que faz ressaltar que o ingresso do discente no programa de monitoria acadêmica é amplo e possibilita uma perspectiva holística da atuação docente.

\section{REFERÊNCIAS}

BOLZAN, D. P. V.; ISAIA, S. M. A.; MACIEL, A. M. R.; Formação de professores: a construção da docência e da atividade pedagógica na educação superior. Rev. Diálogo Educ., v. 13, n. 38, p. 49-68, 2013. 
CUNHA JÚNIOR, F. R. Atividades de monitoria: uma possibilidade para o desenvolvimento da sala de aula. Educação e Pesquisa, v. 43, n. 3, p. 681-694, 2017.

FRISON, L. M. B. Monitoria: uma modalidade de ensino que potencializa a aprendizagem colaborativa e autorregulada. Pro-Posições, v. 27, n. 1, p. 133-153, 2016.

FRISON, L. M. B.; MORAES, M. A. C. As práticas de monitoria como possibilitadoras dos processos de autorregulação das aprendizagens discentes. Poíesis Pedagógica, v. 8, n. 2, p. 144-158, 2011.

HERMEL, E. E. S.; GUNZEL. R. E.; CLERICI, K. S. O PetCiências na Escola: Uma reflexão sobre o papel das aulas práticas no ensino de ciências. Revista Sbenbio: VI Enebio e VII Erebio Regional 3, s/v, n. 9, p. 181-190, 2016.

LIRA, M. O.; NASCIMENTO, D. Q.; SILVA, G. C. L.; MAMAN, A. S. Contribuições da monitoria acadêmica para o processo de formação inicial docente de Licenciandos em Ciências Biológicas da UEPB. Congresso Nacional de Educação, 2, 2015. Disponível em: http://www.editorarealize.com.br/ revistas/conedu/trabalhos/TRABALHO_EV045_MD1_SA18_ID3045_08092015215307.pdf.

Acesso em: 28 maio 2017.

NASCIMENTO, F. B.; BARLETTA, J. B. O olhar do docente sobre a monitoria como instrumento de preparação para a função de professor. Revista Cereus, s/v, n. 5, p. 1-12, 2011.

NUNES, J. B. C. Monitoria acadêmica: espaço de formação. In: SANTOS, M. M.; LINS, N. M. (Org.). A monitoria como espaço de iniciação à docência: Possibilidades e trajetórias. Natal: EDUFRN Editora da UFRN, 2007.

OLIVEIRA, L. A.; ROCHA. J. E.; PEREIRA, V. S. Fatores que levam o aluno a engajar-se em programas de monitoria acadêmica de uma instituição de ensino superior. Revista Interfaces: Saúde, Humanas e Tecnologia, v. 2, n. 2, p. 2014.

PAGEL, U. R.; CAMPOS. L. M.; BATITUCCI, M. C. P. Metodologias e práticas docentes: uma reflexão acerca da contribuição das aulas práticas no processo de ensino-aprendizagem de biologia.

Experiências em Ensino de Ciências, v. 10, n. 2, p. 14-25, 2015.

PEREIRA, G. C. A monitoria como auxílio ao processo de ensino-aprendizagem: um estudo de caso no curso de ciências contábeis da Universidade Federal de Santa Catarina. 2009. 56p. Trabalho de Conclusão de Curso (Graduação em Ciências Contábeis) - Universidade Federal de Santa Catarina, Centro Socioeconômico, Florianópolis-SC, 2009. 
PIMENTA, S. G.; LIMA, M. S. L. Estágio e docência: diferentes concepções. Poíesis Pedagógica, v. 3, n. 3 e 4, p. 5-24, 2006.

PINTO, K. L. J.; SILVA, J. M. C. A formação inicial dos professores para o uso das tecnologias digitais: Uma análise das matrizes curriculares de cursos do Rio Grande do Sul. Revista de educação a distância, v. 3. n. 2. p 227-236, 2016.

SILVEIRA, D. T.; CÓRDOVA, F. P. A pesquisa científica. Métodos de pesquisa, p. 31-42, 2009. Unidade 2.

SOUZA, R. O.; NERY, V. S. C. Formação para docência no ensino superior: Estudos sobre os saberes docentes e os programas de monitorias. MARGENS - Revista Interdisciplinar Dossiê: Formação Docente Versão Digital, v.10. n. 14 p. 75-94 2016.

SPOSITO, M. P.; TARÁBOLA, F. S. Experiência universitária e afiliação: multiplicidade, tensões e desafios da participação política dos estudantes. Educação \& Sociedade, v. 37. n. 137. p. 10091028, 2016.

VASCONCELOS, S. D.; LIMA, K. E. C.; O professor de biologia em formação: Reflexão com base no perfil socioeconômico e perspectiva de licenciandos de uma universidade pública. Ciência e Educação, v. 16, n. 2, p. 323-340, 2010.

VAZ, J. M. C.; PAULINO. A. L. S.; BAZON, F. V. M.; KIILL, K. B.; ORLANDO, T. C.; REIS. M. X. Material didático para ensino de biologia: possibilidades de inclusão. Revista Brasileira de Pesquisa em Educação em Ciências, v. 12, n. 3, p. 81-104, 2012.

VENTURA, A. F.; SILVA, C. J. A.; GALVÃO, B. H. A. Monitoria acadêmica x Docência no ensino superior. Ciências biológicas e da saúde, v. 2, n. 3, p. 35-43, 2015. 
1 Doutorando em Educação pela Universidade Estadual do Ceará. Mestre em Ciências Fisiológicas pela Universidade Estadual do Ceará (2011). Especialista em Educação a Distância pela Universidade Estadual do Ceará, em parceria com a Universidade Aberta do Brasil (2015). Licenciado e Bacharel em Ciências Biológicas na Universidade Estadual do Ceará (2007 - 2008). Atualmente é Professor assistente do curso de Ciências Biológicas da Faculdade de Educação de Crateús (FAEC/UECE). Também atua como tutor à distância e professor formador no Curso de Ciências Biológicas à distância (UECE/UAB). E-mail: jones.baroni@uece.br

2 Graduada em Ciências Biológicas na Faculdade de Educação de Crateús - FAEC/UECE. Especialista em Ensino de Ciências da Natureza e Exatas. Cursando Pedagogia na Faeve em Novo Oriente - CE. Professora de Ciências da rede municipal de ensino de educação fundamental na cidade de Novo Oriente-CE.Técnica em Informática pela EEEP Manoel Mano. E-mail: daniela.mota@aluno.uece.br

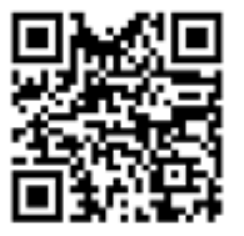

A autenticidade desse artigo pode ser conferida no site https://periodicos. set.edu.br

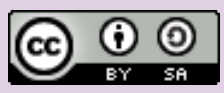

Este artigo é licenciado na modalidade acesso abertosob a Atribuição-Compartilhalgual CC BY-SA

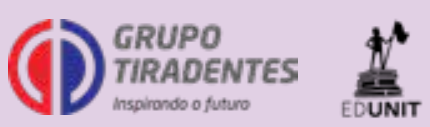

